\title{
Sparsely Granulated Corticotroph Adenoma
}

National Cancer Institute

\section{Source}

National Cancer Institute. Sparsely Granulated Corticotroph Adenoma. NCI Thesaurus.

Code C154340.

A corticotroph adenoma composed of faintly basophilic or chromophobic PAS-positive cells with weak or patchy positivity for ACTH, consistent with the scant, small secretory granules seen ultrastructurally. (WHO 2017) 